\title{
PRESCRIBING TRENDS OF ANALGESICS USED IN POSTOPERATIVE PATIENTS IN A SURGICAL UNIT OF ENAM MEDICAL COLLEGE HOSPITAL
}

\author{
MOHAMMMAD ABDULLAH AL MASUD ${ }^{1}$, ZAIDA RAHMAN $^{2}$, MAHMUDA BEGUM $^{3}$, SYED ASHRAFUZZAMAN ${ }^{4}$ \\ ${ }^{1}$ Assistant Professor, ${ }^{2}$ Associate Professor, ${ }^{3}$ Professor, Department of Pharmacology \& Therapeutics, Enam Medical College, Savar, \\ Dhaka; ${ }^{4}$ Ex Professor, Department of Pharmacology \& Therapeutics, Sir Salimullah Medical College, Mitford, Dhaka
}

\begin{abstract}
The present study was conducted to evaluate the prescribing trends of analgesics used in the postoperative patients in a surgical unit of Enam Medical College Hospital. Treatment records of 180 patients, who underwent surgery in Enam Medical College Hospital, were randomly selected. Data pertaining to pain medications prescribed from the day of operation to sixth postoperative day were recorded. 180 prescriptions containing analgesics were collected randomly from the period of July 2007 to June 2008. In the operation day 65.6\% patients received Nalbuphine and 33.3\% patients received Pethidine. Along with Nalbuphine and Pethidine $86.7 \%$ patients received Tramadol and $13.3 \%$ patients received Ketorolac. $0.6 \%$ patients did not receive any analgesic in the day of operation. In $1^{\text {st }}$ postoperative day, $84.4 \%$ patients received Ketorolac and $15.6 \%$ patients received Tramadol. In $2^{\text {nd, }} 3^{\text {rd }}, 4^{\text {th }}$ and $5^{\text {th }}$ postoperative day patients received Ketorolac $86.1 \%, 85.6 \%, 83.9 \%$ and $62.2 \%$ respectively. In $6^{\text {th }}$ postoperative day, $92.8 \%$ patients did not receive any analgesics.
\end{abstract}

(Bangladesh J Physiol Pharmacol 2009; 25(1\&2) : 23-25)

\section{INTRODUCTION}

Surgical operations are associated with pain, which amplify endocrine and metabolic responses, autonomic reflexes, nausea, ileus and muscle spasm and thereby may increase post operative morbidity and mortality ${ }^{1}$. Optimal post operative pain management is therefore mandatory to enable early mobilization and rehabilitation, to enhance recovery and to reduce morbidity.

Analgesic used preoperatively reduces the dose of general anaesthetics thereby producing balanced anaesthesia and makes better adherence to the treatment with minimal postoperative complications. Postoperative pain management is an important but seemingly undervalued component of perioperative care. Over the past decade, medical societies, governmental agencies, and accrediting bodies such as the Joint Commission on Accreditation of Healthcare Organizations (JCAHO) have paid increasing attention to the management of all types of pain, including postoperative pain².

Despite this increased focus, the literature suggests that many patients continue to experience significant postoperative pain. Inadequately controlled pain can cause postoperative morbidity, prolong recovery time, delay return to normal living, and decrease satisfaction

Address of Correspondence: Dr. Mohammmad Abdullah Al Masud, Assistant Professor, Department of Pharmacology \& Therapeutics, Enam Medical College, Savar, Dhaka with care. Inadequate pain management increases the use of health care resources, thereby increasing total health care costs $^{3}$.

Opioid analgesics have long been shown to produce a dose-dependent reduction in the minimum alveolar anesthetic concentration (MAC) of volatile anesthetics ${ }^{4}$. However, in animal studies designed to assess the effect of Ketorolac on the volatile anesthetic requirement, no reduction in MAC could be demonstrated ${ }^{5}$. Thus, it is not surprising to find that intraoperative anesthetic conditions are generally less satisfactory when Ketorolac is used as an alternative to a potent opioid analgesic ${ }^{6}$.

Despite the failure of NSAIDs to replace opioid analgesics in the management of acute intra- and postoperative pain, these drugs may play a useful role as adjuvant for improving postoperative analgesia. In a placebo-controlled study involving ambulatory surgery patients, Ketorolac 30-60 mg IV given intraoperatively, produced a dose-dependent decrease in postoperative pain scores and opioid analgesic requirements ${ }^{7}$. Post operative pain is one of the most prevalent types of acute pain and is an expected result of surgical procedures experienced by thousands of patients all over the world ${ }^{8}$.

In view of the above considerations and of a scenario in which the practice and the technical decisions of health professionals are increasingly tied to economic restrictions, the present study was designed to evaluate the prescribing pattern of analgesic in a private medical college hospital. 


\section{MATERIALS AND METHODS}

This prospective observational study was carried on 180 patients in a surgical unit of Enam Medical Collage Hospital from July, 2007 to June, 2008.

\section{Selection of Sample}

The prescriptions generated by the graduate and postgraduate doctors to the patients undergoing surgery were included in the study.

The prescriptions which did not contain analgesics were excluded and the prescriptions of the patients suffering from diabetes mellitus, hypertension and any cardiac diseases were also excluded.

\section{Statistical analysis}

Analysis of data was done with the help computer by SPSS program version of 12.0 Software facilities.

\section{RESULTS}

Total number of 180 prescriptions containing analgesics was collected randomly. The distribution of the patients admitted in Enam Medical college hospital according to analgesics used in the operation day were as follows $-65.6 \%$ patients in the hospital received Nalbuphine \& $33.3 \%$ patients received Pethidine in the operation day. Associated analgesics used with Nalbuphine and Pethidine in the operation day were either Ketorolac (13.3\%) or Tramadol (86.7\%). In first post operative day $84.4 \%$ patients received Ketorolac .In $2^{\text {nd }}$, $3^{\text {rd }}, 4^{\text {th }}$ and $5^{\text {th }}$ post operative days patients received Ketorolac $86.1 \%, 85.6 \%, 83.9 \%$ and $62.2 \%$ respectively .In sixth post operative day $92.8 \%$ patients did not receive any analgesics.

Table-I

Distribution of the patients admitted in the Enam Medical College and Hospital according to analgesics used from operation day to sixth post operative day.

\begin{tabular}{|c|c|c|c|c|c|c|}
\hline Day of operation & $\begin{array}{c}\text { Pethidine } \\
(\mathrm{N}=180) \\
\mathrm{N}(\%) \\
\end{array}$ & $\begin{array}{c}\text { Nalbuphine } \\
(\mathrm{N}=180) \\
\mathrm{N}(\%)\end{array}$ & $\begin{array}{c}\text { Tramadol } \\
(\mathrm{N}=180) \\
\mathrm{N}(\%)\end{array}$ & $\begin{array}{c}\text { Ketorolac } \\
(\mathrm{N}=180) \\
\mathrm{N}(\%)\end{array}$ & $\begin{array}{c}\text { Others } \\
(\mathrm{N}=180) \\
\mathrm{N}(\%) \\
\end{array}$ & $\begin{array}{c}\text { Not Used } \\
(\mathrm{N}=180) \\
\mathrm{N}(\%)\end{array}$ \\
\hline Operation Day & 61 (33.9) & $118(65.6)$ & $156(86.7)$ & 24 (13.3) & - & $1(0.6)$ \\
\hline $1^{\text {st }}$ POD & - & - & $28(15.6)$ & $152(84.4)$ & - & - \\
\hline $2^{\text {nd }} P O D$ & - & - & $25(13.9)$ & 155 (86.1) & - & - \\
\hline $3^{\text {rd }}$ POD & - & - & $26(14.4)$ & $154(85.6)$ & - & - \\
\hline $4^{\text {th }}$ POD & - & - & $29(16.1)$ & 151 (83.9) & - & - \\
\hline $5^{\text {th }}$ POD & - & - & $23(12.8)$ & $112(62.2)$ & - & $45(25)$ \\
\hline $6^{\text {th }}$ POD & - & - & $3(1.7)$ & $10(5.6)$ & - & $167(92.8)$ \\
\hline
\end{tabular}

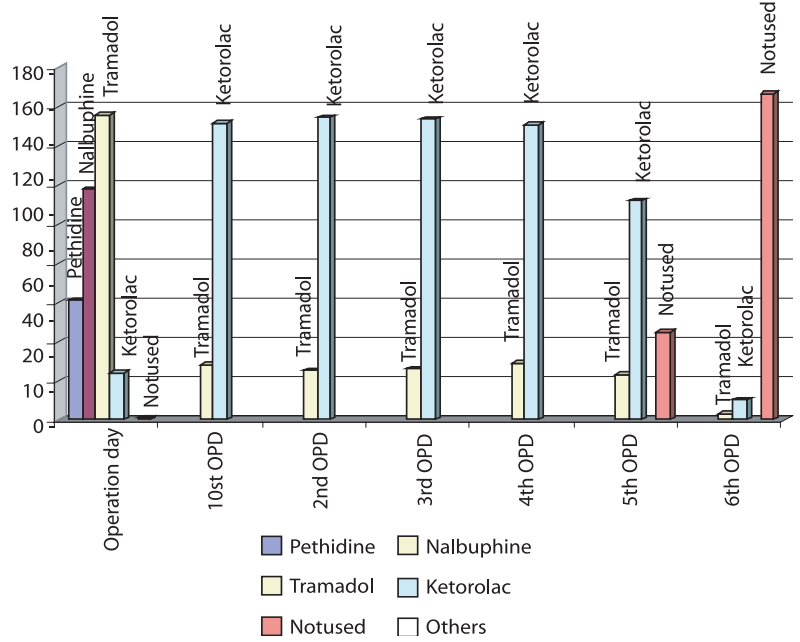

Fig.-I: Distribution of patients admitted in Enam Medical college \& Hospital according to analgesics used from the day of operation to $6^{\text {th }} P O D(N=180)$

\section{DISCUSSION}

The present study reveals that Nalbuphine was mostly used in the day of operation. Possibly Nalbuphine was used in this private hospital because patient has to purchase Pethidine from outside, which is expensive than Nalbuphine and difficult to obtain because Pethidine is a regulated product. One previous study found that the Nalbuphine has a longer duration of action than Pethidine while pain intensity and visual analogue scales were considered. They also found that the respiration rates in the Pethidine group were significantly more depressed after the injection than in the Nalbuphine group. Nalbuphine caused less depression of both systolic and diastolic blood pressure at both 30 and 60 minutes $^{9}$.

Another study proposed that Nalbuphine is a suitable alternative to Pethidine, producing beneficial sedation which is maximum at 60 min after injection. However, 
they also reported nausea and vomiting of delayed onset as a disadvantage of Nalbuphine ${ }^{10}$.

Although NSAIDs are unable to replace opioid analgesics in the management of acute intra- and postoperative pain, these drugs may play a useful role as adjuvant for a dose-dependent decrease in postoperative pain scores and opioid analgesic requirements ${ }^{7}$.

Nalbuphine was used mostly on the operation day and Ketorolac was used on later post operative days. This is due to the better adherence to Ketorolac by the patients due to its no severe side effects such as no cardio respiratory depression with no addiction liability as compared to Pethidine or Nalbuphine. Moreover Ketorolac is widely available and cheaper than Pethidine or Nalbuphine and Ketorolac is also available in oral form.

Standard Treatment Guideline should be introduced to avoid individual's empirical selection of analgesic so that working doctors adhere to it and prescribe rationally thereby improving the health care delivery system with minimal cost and adverse effects.

\section{REFERENCES}

1. Kehlet H. Acute pain control and accelerated post operative surgical recovery. Surg Clin N Am. 1999; 79: 431-43.
2. Ritchey RM. Optimizing post operative stoperative pain management. Cleveland Clinic J Med 2006; 73: s72-s76.

3. Joshi PG, Ogunnaike BO. Consequences of inadequate post operative pain relief and chronic persistent post operative pain. Anesthesiol Clin North Am. 2005; 23: 21-36.

4. Hoffman JC, DiFazio CA. The anesthesia sparing effect of pentazocine, meperidine and morphine. Arch Int Pharmacodyn Ther 1970; 18: 261-8.

5. Rich GF, Schacterle R, Moscicki JC, DiFazio CA. Ketorolac does not decrease the MAC of halothane or depress ventilation in rats. Anesth Analg.1992; 75: 99-102.

6. Ding Y, White PF. Simplified quality of anaesthesia scoring system. Anesthesia 1992; 47: 906-7.

7. Souter AJ, Fredman B, White PF. Controversies in the Perioperative Use of Nonsterodial Anti-inflammatory Drugs. Anesth Anal 1994; 79: 78-90.

8. Ashburn MA, Ready LB. Postoperative pain. In: Loeser JD, Butler S, Chapman CR, Turk DC (ed.). Bonica'smanagement of pain. Philadelphia: Lippincott Williams \& Wilkins. 2001; p.765-79.

9. Yasin B, Asghar M. Nalbuphine compared to Pethidine for postoperative pain relief after Orthopaedic surgery. Anesth Pain Intens Care.2005; 9: 3-6.

10. Chestnutt WN, Clarke RSJ, Dundee JW. Comparison of Nalbuphine, Pethidine and Placebo as Premedication For Minor Gynaecological Surgery. Br J Anaes.1987; 59: 576580. 